\title{
Copper deposition on Pd membranes by electroless plating
}

\author{
E. Aacha ${ }^{1}$ \\ Y.C. van Delft \\ J. Overbeek \\ P.L. Arias ${ }^{1}$ \\ J.F. Cambra ${ }^{1}$
}

${ }^{1}$ Chemical Engineering and Environmental Department, University of the Basque Country (UPV/EHU), 48013 Bilbao, Spain

Published in International Journal of Hydrogen Energy, Volume 36, 2011,

pages 13114-13121 
Provided for non-commercial research and education use. Not for reproduction, distribution or commercial use.

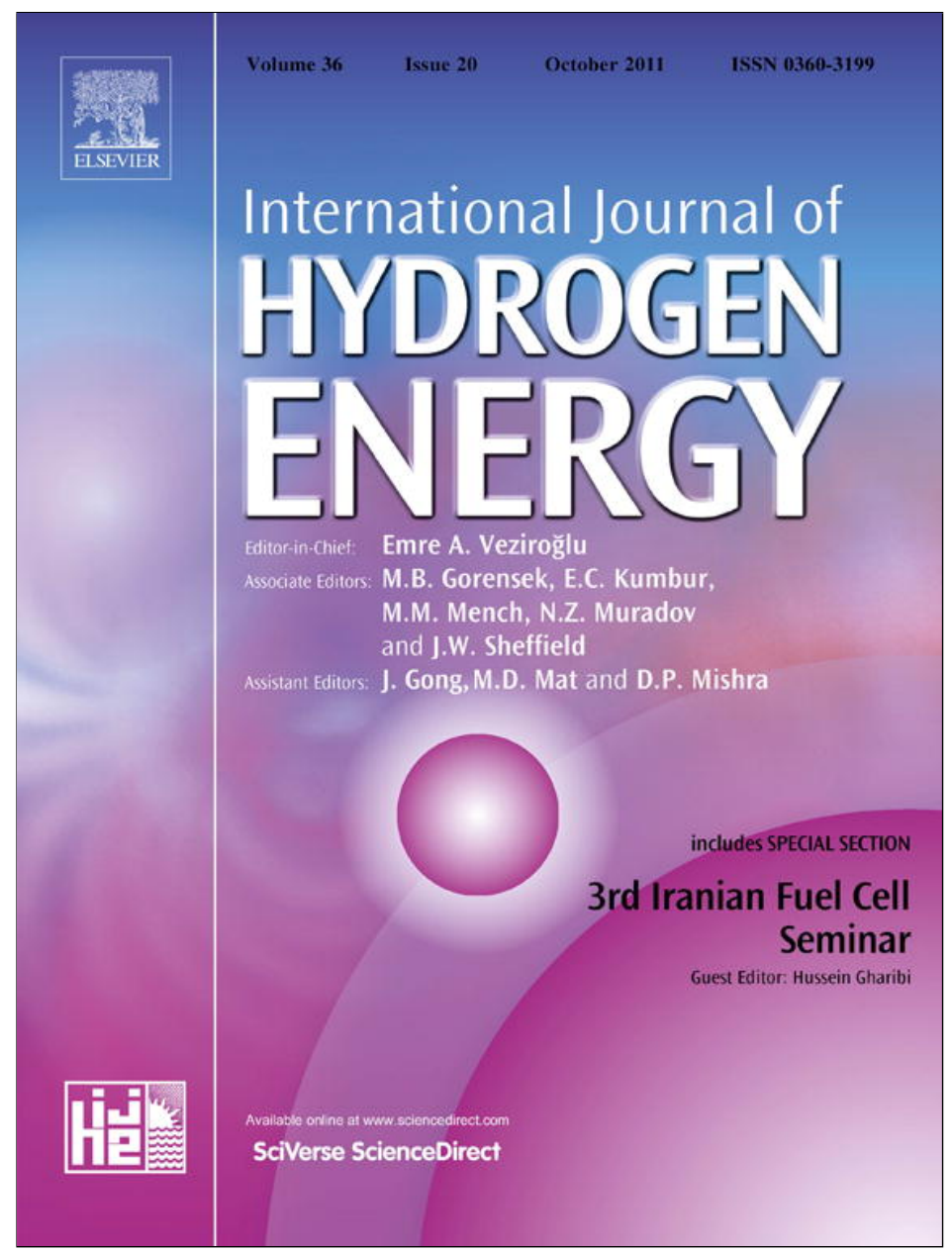

This article appeared in a journal published by Elsevier. The attached copy is furnished to the author for internal non-commercial research and education use, including for instruction at the authors institution and sharing with colleagues.

Other uses, including reproduction and distribution, or selling or licensing copies, or posting to personal, institutional or third party websites are prohibited.

In most cases authors are permitted to post their version of the article (e.g. in Word or Tex form) to their personal website or institutional repository. Authors requiring further information regarding Elsevier's archiving and manuscript policies are encouraged to visit:

http://www.elsevier.com/copyright 


\title{
Copper deposition on Pd membranes by electroless plating
}

\author{
E. Acha ${ }^{a, *}$, Y.C. van Delft ${ }^{b}$, J. Overbeek ${ }^{b}$, P.L. Arias ${ }^{a}$, J.F. Cambra ${ }^{a}$ \\ ${ }^{a}$ Chemical Engineering and Environmental Department, University of the Basque Country (UPV/EHU), 48013 Bilbao, Spain \\ ${ }^{\mathrm{b}}$ Energy Research Centre of the Netherlands (ECN), Netherlands
}

\section{A R T I C L E I N F O}

\section{Article history:}

Received 28 January 2011

Received in revised form

12 July 2011

Accepted 16 July 2011

Available online 11 August 2011

\section{Keywords:}

Hydrogen selective membranes

$\mathrm{PdCu}$

Alloying

Electroless plating

Purification

\begin{abstract}
A B S T R A C T
PdCu membranes were prepared by the electroless plating of Pd membranes prepared on ceramic tubular supports. Different PdCu membranes were prepared with Pd content between 45 and $77 \mathrm{wt} \%$ and a total metal layer between 0.5 and $1.9 \mu \mathrm{m}$ thickness. The alloying step was performed in two ways to compare and establish the required alloying time for obtaining high permeance membranes. The alloying was analysed with EDX composition measurements, and full alloying was not required to obtain a stable hydrogen flux. Finally, permeance tests were performed at different pressures, including temperature cycles in hydrogen and nitrogen, to observe membrane stability. The hydrogen permeance values of the membranes were high, between $1.5 \times 10^{-3}$ and $4.5 \times 10^{-3} \mathrm{~mol} /$ $\left(\mathrm{s} \mathrm{Pa}^{0.5} \mathrm{~m}^{2}\right.$ ) at $673 \mathrm{~K}$. The membranes recorded stable permeance values even after thermal cycles in a hydrogen atmosphere. Metal layer thickness was calculated using both the weight difference method and SEM images. SEM images were also used to analyse the surface morphology of the membranes, which was generally fairly uniform and smooth. Copyright @ 2011, Hydrogen Energy Publications, LLC. Published by Elsevier Ltd. All rights reserved.
\end{abstract}

\section{Introduction}

Hydrogen production is increasing as it is a valuable commodity in refining and petrochemical processes; it is also a promising energy carrier, via fuel cells, for reducing air pollution in the automobile sector [8]. Within this scenario, hydrogen selective membranes are viable and promising candidates for hydrogen purification processes due to their high permeability, especially Pd-based membranes. Pd has the ability to dissociate the hydrogen molecules in hydrogen atoms, whereby the membrane separates the hydrogen from other gases. Nevertheless, in practice, certain mechanical problems arise due to hydrogen embrittlement. At temperatures below $573 \mathrm{~K}$, and pressures below $2.0 \mathrm{MPa}$ [16] the $\beta$ hydride may nucleate from the $\alpha$ phase. This results in severe lattice strains (from the $\alpha$ to $\beta$ phases the lattice expands by about $4 \%$, and as a result pure palladium membranes become brittle after a few cycles of $\alpha \leftrightarrow \beta$ transitions [12].

In order to solve, or minimize, the problem of hydrogen embrittlement, different Pd alloys have been studied, such as silver, gold, nickel and copper based ones $[4,33,35]$. The PdCu alloy is being widely studied due to its better resistance to hydrogen sulphide and sulphurous components [14] observed that $\mathrm{PdCu}$ membranes recorded higher $\mathrm{H}_{2}$ permeance than similar Pd membranes and also a higher resistance to $\mathrm{H}_{2} \mathrm{~S}$. The $\mathrm{PdCu}$ alloy phase diagram has been reported in the literature [27]. This alloy can form two different crystal structures: bcc and fcc. The ordered bcc structure is formed at temperatures below $873 \mathrm{~K}$ in the composition domain from 50 to $70 \mathrm{~mol} \%$ of $\mathrm{Cu}$. A two-phase domain is found in the neighbouring composition ranges. The disordered fcc phase is formed for the other composition ranges.

\footnotetext{
* Corresponding author. Tel.: +34 946014050.

E-mail address: esther.acha@ehu.es (E. Acha).
} 0360-3199/\$ - see front matter Copyright @ 2011, Hydrogen Energy Publications, LLC. Published by Elsevier Ltd. All rights reserved. doi:10.1016/j.ijhydene.2011.07.068 
The influence the PdCu alloy composition has on its hydrogen permeance has been widely studied. The structure change of the PdCu alloy means a restructuring of the Pd and $\mathrm{Cu}$ atoms, which affects the permeability of the membrane. Hydrogen permeation through metal dense membranes is influenced by the thickness of the metal layer, temperature, alloy composition (a permeability peak is observed with a composition of around $40 \mathrm{wt} \%$ of $\mathrm{Cu}$ ), pressure difference across the membrane, and support, amongst others $[20,28,29,38,39]$. In general, bcc phase membranes are more permeable to hydrogen due to its tetrahedral configuration, as compared to the octahedral configuration for the fcc phase [3].

There are different ways of producing PdCu membranes such as: electroless plating, electro-plating, physical vapour deposition (PVD sputtering) and chemical vapour deposition (CVD). Among all these techniques, electroless plating is the one most studied [18] found that the permeance obtained with membranes prepared by electroless plating was higher than when other techniques were used. This technique requires minimal equipment, no exotic precursors and it can be performed on any appropriately activated surface without a power supply. A disadvantage of this technique is that simultaneous $\mathrm{Pd}$ and $\mathrm{Cu}$ plating (co-plating) is very difficult [2], so both sequential plating and, therefore, alloying are required. The alloying should be performed in such a way that the alloy composition in the metal layer is uniform to avoid embrittlement. Accurate control of the plated metal layer thicknesses is also required to obtain a given alloy composition.

The objective of this work was to prepare a large flux $\mathrm{PdCu}$ membrane by the sequential electroless plating of a thin $\mathrm{Cu}$ layer on a Pd plated porous ceramic support. A study was made of the influence the preparation steps have on membrane performance and stability (thermal cycles). Accordingly, Scanning Electron Microscopy (SEM) images of the surface morphology and metal layer were taken before and after each preparation step. The PdCu composition in the cross-section metal layer was measured with EDX to analyse the alloying process. The membranes prepared in this work had a targeted thickness of less than $5 \mu \mathrm{m}$.

\section{Experimental procedure}

\subsection{Membrane preparation}

PdCu alloy membranes were prepared by sequential electroless plating. The initial membranes used in this work were Pd over an alumina tubular support, with an outside diameter of $14 \mathrm{~mm}$ and a wall thickness of $3 \mathrm{~mm}$, consisting of a multiple layer structure with a top layer of $\alpha-\mathrm{Al}_{2} \mathrm{O}_{3}$ with a $90 \mathrm{~nm}$ pore size. Pd membranes were prepared following the procedure reported by [9]. This work will consider only Cu deposition and alloying.

The reactants used for the metal and reducing solutions for the copper plating are reported in Table 1 , which are a simplified recipe of the ones found in the literature [30]. In the case of the Cu electroless plating of a Pd membrane, the Pd layer itself is the active surface. When using formaldehyde as a reducing agent, the effect of $\mathrm{pH}$ is significant, with its optimum value falling between 12 and 14, and significant also

\begin{tabular}{ll} 
Table 1 - Electroless Cu plating bath. & \\
\hline Solution & \multicolumn{1}{c}{ Constituent } \\
\hline Metal solution & $\mathrm{CuSO}_{4} \cdot 5 \mathrm{H}_{2} \mathrm{O}$ \\
& $\mathrm{Na}_{2} \mathrm{EDTA}$ \\
& $\mathrm{NaOH}$ \\
& Triton X-100 \\
& \\
& Formaldehyde (37\%) \\
Reducing solution & Milli Q water
\end{tabular}

is the temperature control of the plating bath [24]. The overall $\mathrm{Cu}$ electroless plating reaction is theoretically described in Equation (1). The amount of solution was prepared according to the membrane length. The metal solution was prepared the day before actual plating and remained under shaking regime during that time.

$\mathrm{Cu}^{2+}+2 \mathrm{HCHO}+4 \mathrm{OH}^{-} \leftrightarrow \mathrm{Cu}^{0}+\mathrm{H}_{2}+2 \mathrm{H}_{2} \mathrm{O}+2 \mathrm{HCO}_{2}^{-}$

For the copper plating, the tubular Pd membranes were hermetically sealed inside. The metal solution was put into a plating bath equipped with a heating unit that kept the temperature constant. When the metal solution was at the desired temperature, $318 \mathrm{~K}$, the reducing solution was added to the bath and the electroless plating process started. The solution was carefully shaken during plating. All the plating solutions used for the $\mathrm{PdCu}$ preparation were stable, given the $[\mathrm{EDTA}] /\left[\mathrm{CuSO}_{4}\right]$ and $[\mathrm{NaOH}] /\left[\mathrm{CuSO}_{4}\right]$ ratios used [34].

When the desired plating time had elapsed, the membranes were rinsed and dried at $333 \mathrm{~K}$. Membranes were weighed before and after the plating process to measure the weight increase with a view to estimating the amount of copper deposited. The PdCu layers were then alloyed in an inert atmosphere at $673 \mathrm{~K}$ for $150 \mathrm{~h}$, according to the procedure proposed in [13]. The alloying step is crucial in $\mathrm{PdCu}$ membranes, since Pd dissociates the hydrogen molecules into two atoms. If $\mathrm{Cu}$ is on the outside of the metal layer there will be no hydrogen flux through it. The $\mathrm{Pd}$ and $\mathrm{Cu}$ atoms mix during and after the alloying process $[1,17,40]$ and the required temperature and alloying time will vary depending on the metal layer thickness $[19,23,31]$. For comparing and verifying of the alloying method, two of the prepared membranes were alloyed in a gas permeation system. This experiment simulated the alloying conditions, with the same heating rate and inert atmosphere and with hydrogen permeation measures in between.

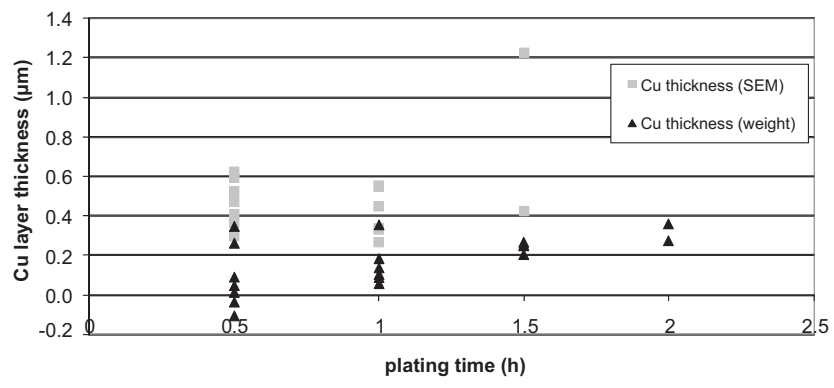

Fig. 1 - Comparison of the $\mathrm{Cu}$ thickness obtained at different plating times. 

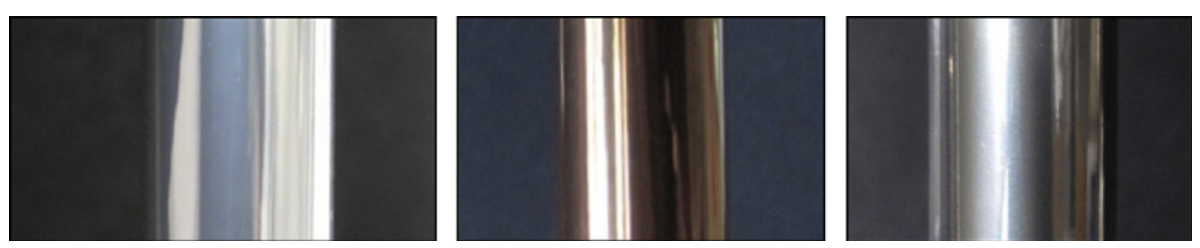

Fig. 2 - Membrane colour before Cu plating (left), after plating (middle) and after alloying (right). (For an interpretation of the references to colour in this figure legend, the reader is referred to the web version of the article).

All the prepared membranes were checked with a simple nitrogen test to detect metal layer defects that could influence membrane permeance and selectivity results. This test was conducted before and after $\mathrm{Cu}$ plating, after alloying and after the hydrogen permeance tests in order to control the effect of the steps on membrane morphology (defect formation). For the leak tests, the ends of the membranes were sealed and the membranes were then filled with nitrogen at 3 bar.

\subsection{Permeance measurements}

The hydrogen permeance of $10 \mathrm{~cm}$ long membranes $\left(\mathrm{mol} \mathrm{H}_{2} \mathrm{~m}^{-2} \mathrm{~s}^{-1} \mathrm{~Pa}^{-\mathrm{n}}\right)$ was measured in a Gas Permeation System (GPS). This system, which includes a dead end module with bleed flow, can control feed and permeate pressure, temperature, and feed gas type and flow. Before starting the hydrogen permeance tests, a leak test was conducted with $\mathrm{N}_{2}$ at $298 \mathrm{~K}$, as a reference, and then the membranes were heated, in $\mathrm{N}_{2}$ to $673 \mathrm{~K}$. Once at the desired temperature, another $\mathrm{N}_{2}$ leak test was carried out. The membranes were then kept in hydrogen followed by permeation readings, at 9, 7, 5 and 3 bar feed pressure with 2 bar of pressure difference across the membrane. These measurements were repeated three times. The membranes were then cooled to $423 \mathrm{~K}$ and subsequently heated again to $673 \mathrm{~K}$ in $\mathrm{N}_{2}$ followed by three permeance measurements in a hydrogen atmosphere. The next step involved cooling and heating the membranes again, but this time in $\mathrm{H}_{2}$. Finally, before the last cooling, three measurements were taken of hydrogen permeance at different feed pressures.

\subsection{Membrane characterization}

Different membrane parameters were measured: the thickness of the Pd and Cu metal layers, the surface morphology of

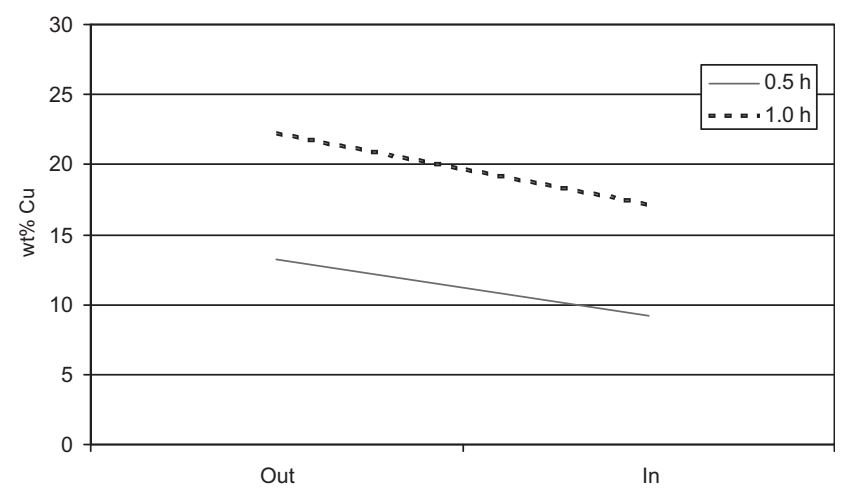

Fig. 3 - EDX composition of two membranes on the outside and inside of the metal layer after alloying. the metal layer and the alloy composition. The $\mathrm{Cu}$ layer thickness values obtained using the weight difference technique were compared to the ones determined by SEM. The weight difference method is non-destructive, but as the layers were very thin its accuracy was low.

The composition of the alloyed membranes was calculated from the metal layer thickness measured with Field-Emission SEM (JEOL JSM 6550F with $8 \mathrm{~nm}$ resolution). The thickness of the $\mathrm{Pd}$ and $\mathrm{Cu}$ was measured at different points on a cut ring, and the average of these values was calculated. To analyse the alloying of the metals, the composition was measured by Electron Dispersive X-Ray analysis (EDX) of the outside and inside of the metal layer. EDX measures an average composition of $1 \mu \mathrm{m}$ layer. As the metal layers of the prepared membranes in this work were around 1-2 $\mu \mathrm{m}$, these values were not exact, but these data allowed a rough analysis of metal diffusion during alloying.

Membrane morphology was analysed firstly by visual observation of the brightness [36] and secondly using SEM images. These images were obtained after $\mathrm{Cu}$ plating, after alloying and after the permeance tests, in order to check how the surface changed throughout the entire process. The intensity of the electrons used in the SEM images was $15 \mathrm{kV}$.

\section{Results and discussion}

\subsection{Kinetic study of the Cu plating of a Pd membrane}

It is important to know the amount of $\mathrm{Cu}$ that will be plated in a fixed period of time, in order to predict the final alloy composition. The thickness of the Cu plated was measured in two ways, namely, weight analysis and SEM analysis. Fig. 1 shows the $\mathrm{Cu}$ thickness calculated with the two methods after the different $\mathrm{Cu}$ plating times of the Pd membranes.

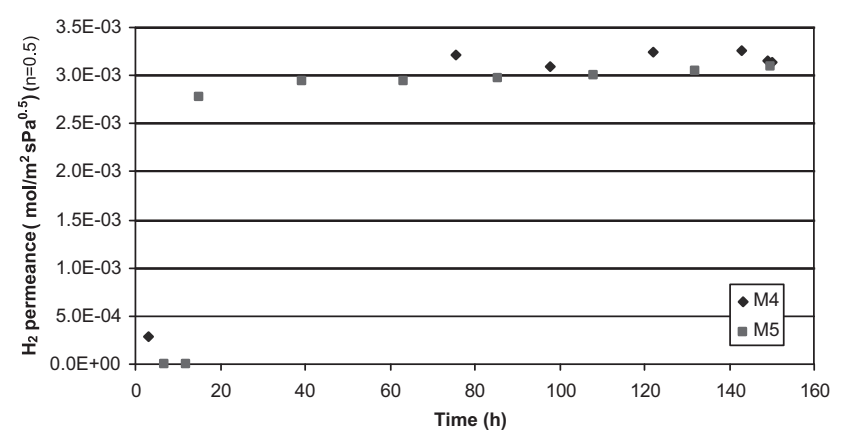

Fig. 4 - Hydrogen flow through the membranes while alloying in inert gas. 


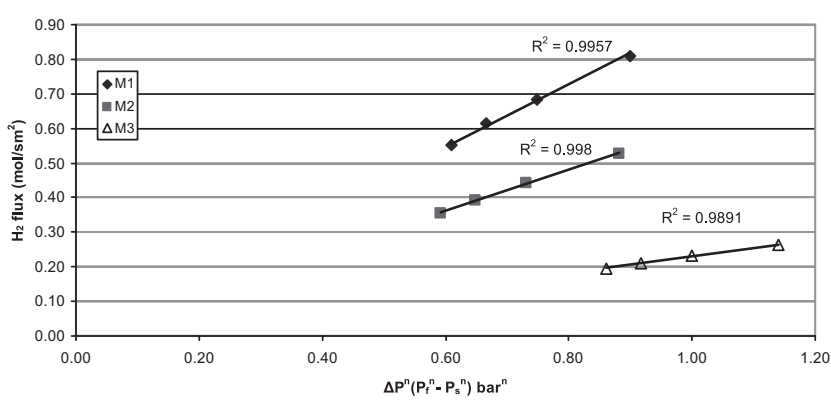

Fig. 5 - Hydrogen permeance results for PdCu membranes at $673 \mathrm{~K}$ using the experimental $\mathrm{n}$ value.

There was no direct and repetitive correlation between time and thickness. There was a general tendency for the thickness calculated from weight differences: the plating rate increased at the beginning, then stabilized and, finally, prolonged plating times did not result in further $\mathrm{Cu}$ deposition.

Both methods for determining the layer thickness had mayor experimental limitations, even leading to the recording of negative values using the weight method. This was probably due to atmospheric conditions and to the fact the weight gained was very small compared to the membranes' total weight. Differences between the thickness calculated with the weight difference method and the SEM images have also been reported in the literature [25]. The thickness calculated with the SEM images was the average of three or four measurements, with a standard deviation lower than $0.2 \mu \mathrm{m}$. Regarding the weight values, an error of $1 \mathrm{mg}$ in the measured weight would have involved a standard deviation of $0.018 \mu \mathrm{m}$. In this case, as the Pd is already on top of the membrane, metal thicknesses measured by SEM images were used for the composition estimations of the prepared membranes.

\subsection{Alloying of membranes}

After $\mathrm{Cu}$ deposition, $\mathrm{Pd}$ and $\mathrm{Cu}$ were alloyed to obtain the desired composition and $\mathrm{H}_{2}$ permeance characteristics. The

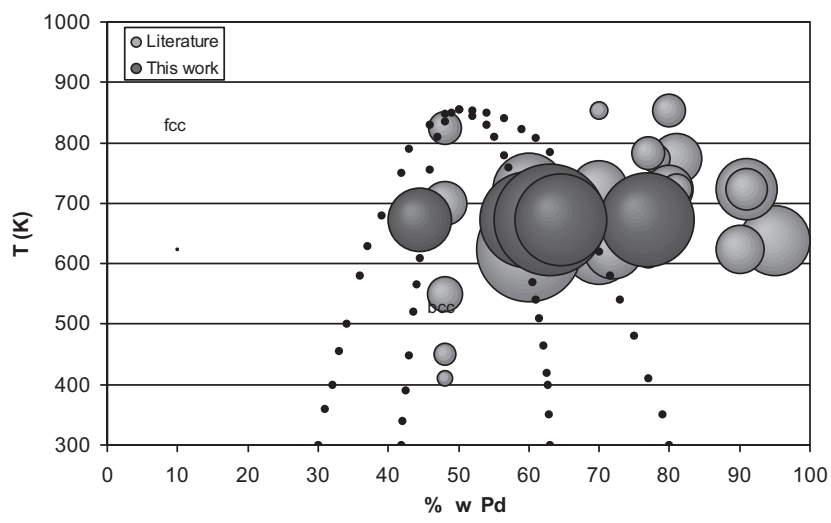

Fig. 6 - Comparison of the permeance values of the PdCu prepared in this work with the ones reported in the literature. Circle diameter is proportional to the permeance value. Small points represent phase limits.

diffusion of the metals was visually monitored as the colour changed from $\mathrm{Cu}$ colour, before alloying, to Pd colour after alloying, see Fig. 2.

The composition of the outside and inside of the alloyed metal layer of some of the membrane rings was analysed with EDX to study metal diffusion during alloying. PdCu composition was measured from a cross-section of the metal layer. Fig. 3 shows the EDX results for two of the prepared membranes with different $\mathrm{Cu}$ plating times, 0.5 and $1.0 \mathrm{~h}$. Before alloying, all the $\mathrm{Cu}$ was on the outside and the Pd was on the inside of the metal layer. Although after alloying there still was more $\mathrm{Cu}$ on the outside of the membrane than inside, metal diffusion during alloying was monitored. All the membranes analysed followed the same pattern when comparing the EDX composition before and after alloying.

Fig. 4 presents the results for the membranes alloyed in the GPS with hydrogen tests in between to check the increase in permeance and the required alloying time. $\mathrm{H}_{2}$ permeance was zero at the beginning of both tests, when $\mathrm{Cu}$ was outside, and after a sharp increase at around $15 \mathrm{~h}$ it continued increasing,

Table 2 - Hydrogen permeation performance of PdCu and Pd membranes reported in previous literature and in this work.

\begin{tabular}{|c|c|c|c|c|c|c|c|}
\hline & wt\% Pd & PdCu or Pd layer $(\mu \mathrm{m})$ & Temperature (K) & Permeability $\mathrm{mol} / \mathrm{smPa}^{\mathrm{n}}$ & Selectivity & $\mathrm{n}$ & Ref. \\
\hline M1-PdCu & 63.0 & 1.025 & 673 & $1.8 \times 10^{-9}$ & $>300$ & $0.653^{\mathrm{a}}$ & c \\
\hline $\mathrm{M} 2-\mathrm{PdCu}$ & 64.5 & 1.450 & 673 & $2.1 \times 10^{-9}$ & $>400$ & $0.645^{\mathrm{a}}$ & c \\
\hline M3-PdCu & 44.4 & 0.942 & 673 & $9.9 \times 10^{-11}$ & $>100$ & $0.748^{\mathrm{a}}$ & c \\
\hline $\mathrm{M} 4-\mathrm{PdCu}$ & 59.8 & 1.000 & 673 & $9.2 \times 10^{-10}$ & $>450$ & & c \\
\hline M5-PdCu & 76.9 & 0.934 & 673 & $1.4 \times 10^{-9}$ & $>1000$ & & c \\
\hline $\mathrm{PdCu} / \mathrm{PSS}$ & 90 & 5 & 673 & $2.1 \times 10^{-9}$ & $<4$ & 0.6 & [6] \\
\hline $\mathrm{PdCu} / \mathrm{PSS}$ & 59 & 10 & 673 & $7.7 \times 10^{-13}$ & $\infty$ & 1 & [6] \\
\hline $\mathrm{PdCu} / \mathrm{Al}_{2} \mathrm{O}_{3}$ & 92 & 5.0 & 753 & $1.4 \times 10^{-11}$ & $>1000$ & 1 & {$[40]$} \\
\hline $\mathrm{PdCu} / \mathrm{Al}_{2} \mathrm{O}_{3}$ & 95 & 7.0 & 753 & $1.6 \times 10^{-11}$ & 900 & 1 & [40] \\
\hline $\mathrm{Pd}$ & & 0.35 & 673 & $1.1 \times 10^{-12}$ & 1140 & 1 & [37] \\
\hline $\mathrm{Pd}$ & & 10 & 740 & $2.8 \times 10^{-9}$ & 970 & 0.65 & [15] \\
\hline $\mathrm{Pd}$ & & 1 & 683 & $1.3 \times 10^{-11}$ & 400 & 1 & [11] \\
\hline $\mathrm{Pd}$ & & 5 & 723 & $2.6 \times 10^{-6 b}$ & 3700 & ns & [10] \\
\hline
\end{tabular}

a Average $\mathrm{n}$ value calculated from the experimental data.

$\mathrm{b}$ Permeability value calculated from the data in the article assuming standard conditions and $\mathrm{n}$ value of 0.5 .

c This work. 


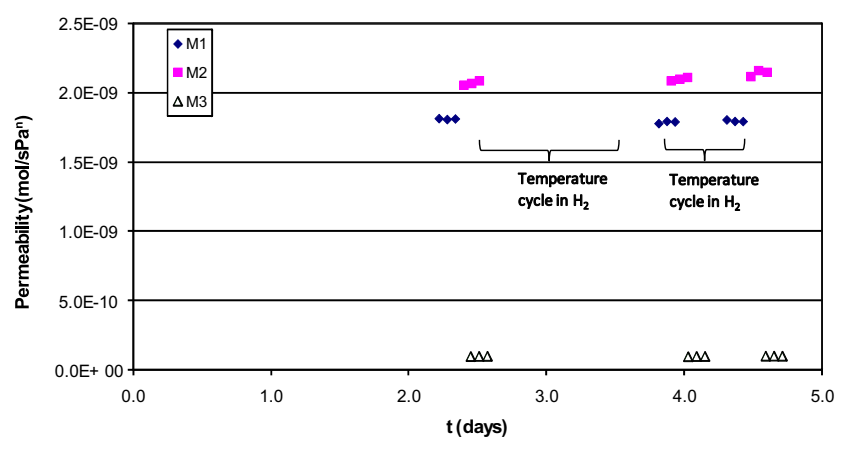

Fig. 7 - Hydrogen permeability stability with temperature cycling at $673 \mathrm{~K}$. A thermal cycle was performed in nitrogen between first and the second groups of data and in hydrogen between the second and third groups of data.

albeit much more slowly. As no permeance occurs when $\mathrm{Cu}$ is on top of the metal layer, the beginning of $\mathrm{H}_{2}$ permeance could be attributed to the presence of some Pd on the surface. Therefore, around $20 \mathrm{~h}$ in an inert atmosphere sufficed for alloying these membranes of around $1 \mu \mathrm{m}$ metal thickness.

\subsection{Gas permeation measures}

This section will discuss the influence the variation in the $\mathrm{H}_{2}$ feed pressure has on permeation behaviour. The permeation of the prepared membranes was tested at different feed pressures after $\mathrm{H}_{2}$ activation and with cooling cycles. The hydrogen flux values of the membranes M1, M2 and M3 shown in Fig. 5 were measured at $673 \mathrm{~K}$ with 2 bar pressure difference across the membrane. The experimentally calculated $n$ value was used in the $\Delta \mathrm{P}^{\mathrm{n}}$ calculation. Richardson's equation (Equation (2)) was followed at all the feed pressures tested. This can be observed from the correlation index values obtained from linear regression, close to 1. Richardson's equation is based on Sieverts' Law, with the exponent equal to 0.5 reflecting the dissociation of the gaseous hydrogen molecule into two hydrogen atoms that diffuse into the metal [21]. The highest hydrogen flux, $0.81 \mathrm{~mol}^{1} \mathrm{~s}^{-1} \mathrm{~m}^{-2}$, was obtained for the M1 membrane at 3 bar on the feed side and 1 bar on the permeate side of the membrane.

$J_{i}=\frac{P_{o}}{l} \exp \left[\frac{-E a}{R T}\right]\left(P_{\text {feed }}^{n}-P_{\text {perm }}^{n}\right)$

Table 2 shows the hydrogen permeation performance of the five PdCu membranes tested in the GPS. All the membranes prepared in this work were tested at $673 \mathrm{~K}$ and with 2 bar difference pressure. As shown in Table 2, these membranes had a good permeation performance as compared with the reported values for alloyed PdCu and Pd membranes in the literature. The selectivity of the tested membranes was high, $>300 \mathrm{mLH}_{2} / \mathrm{mLN}_{2}$, and the thickness of the metal layers was around $0.9-1.5 \mu \mathrm{m}$. The experimental values of the $\mathrm{n}$ coefficient, for a better correlation between permeance values and pressure differences across the membrane, were between 0.64 and 0.74 . As the membrane thickness decreases, the pressure exponent is expected to be higher than 0.5 , as occurred with the membranes prepared in this work. The hydrogen transport through Pd-based membranes occurs via a solution and diffusion mechanism, including several surface processes and bulk diffusion. These two processes could be the rate-determining step for hydrogen permeation [5]. If the pressure exponent is close to 1 , this indicates that the surface reactions become ratelimiting in hydrogen transport $[16,26]$. For $n$ values between 0.5 and 1, both the surface and bulk diffusion processes are responsible for hydrogen flux resistance [32] compared Pd membrane thickness and $\mathrm{n}$ values and found that for thicknesses of less than $10 \mu \mathrm{m}$ the $\mathrm{n}$ value is higher than the theoretical one of 0.5 . The $n$ value is not only affected by the thickness of the metal layer, but also by, amongst others, the preparation method, surface composition, mass transfer resistance and experimental conditions [40].

Fig. 6 compares the permeance values obtained in this work (darker cycles) with the ones from the literature for PdCu alloys on ceramic supports (lighter colour), depending on the membrane composition and temperature. The permeance values of the membranes reported in this work, proportional to circle diameter, were consistent with the literature. The membrane with $45 \mathrm{wt} \% \mathrm{Pd}$ is the one with the lowest permeance value, and the ones around $60 \mathrm{wt} \% \mathrm{Pd}$ are the ones with the highest values, as expected from the literature $[3,20]$. Nevertheless, permeance is influenced by so many variables that it is not easy to establish a maximum permeance membrane simply specifying its composition. At $673 \mathrm{~K}$ and with the composition calculated from the SEM images, the membranes with the highest theoretical permeance values had bcc + fcc and fcc structures. The membrane with the lowest Pd percentage ( $44.4 \mathrm{wt} \% \mathrm{Pd}$ ) was also the one with the lowest permeance value, and it had a bcc + fcc structure.

Temperature cycles were performed in inert and hydrogen atmospheres to test the stability of the prepared $\mathrm{PdCu}$ membranes. Fig. 7 shows the permeability values of three of the tested membranes in the GPS: M1, M2 and M3. On around the third day, the membranes were cooled to $423 \mathrm{~K}$ and heated
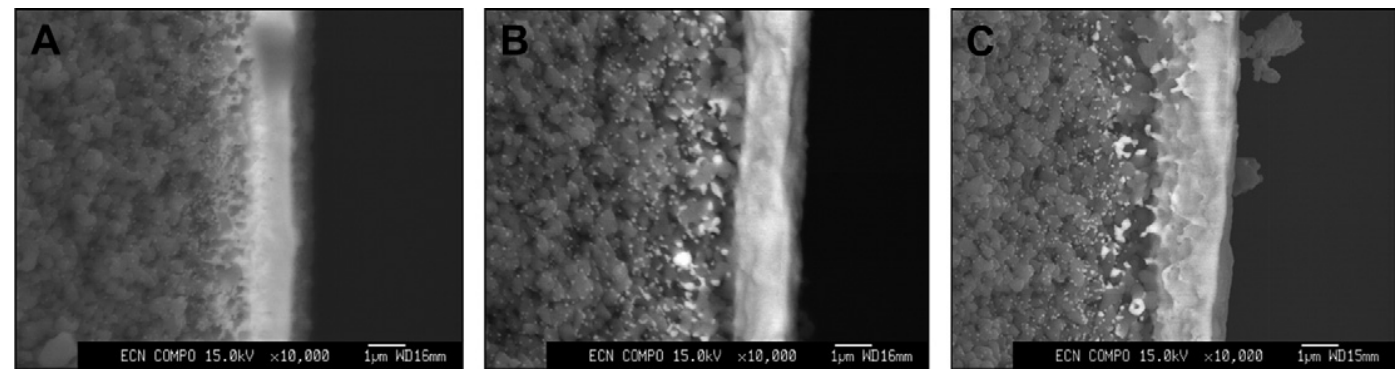

Fig. 8 - SEM image of the M2 after plating (A), after alloying (B), and after the hydrogen permeance test (C). 

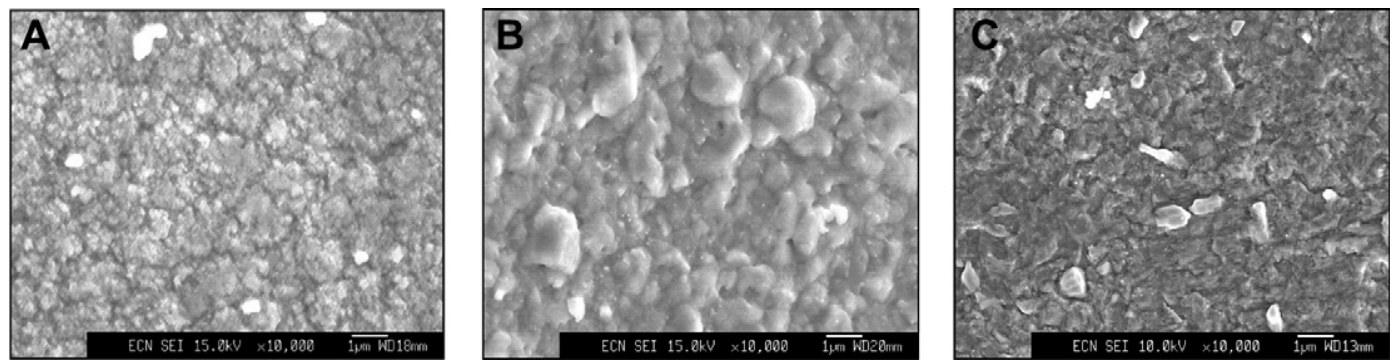

Fig. 9 - SEM images of the M2 surface morphology after Cu plating (A), after alloying (B) and after the hydrogen permeance test in the GPS (C).

\begin{tabular}{|c|c|c|c|}
\hline & & Out Cu wt\% & In $\mathrm{Cu}$ wt\% \\
\hline \multirow[t]{2}{*}{ M2 } & After alloying & 5.10 & 2.31 \\
\hline & After $\mathrm{H}_{2}$ test & 5.28 & 5.57 \\
\hline \multirow[t]{2}{*}{ M1 } & After alloying & 7.82 & 2.17 \\
\hline & After $\mathrm{H}_{2}$ test & 6.43 & 3.84 \\
\hline
\end{tabular}

again to $673 \mathrm{~K}$ in an inert atmosphere. Between the fourth and the fifth days, the same thermal cycle was performed, but this time in a hydrogen atmosphere. As can be observed, the permeability of the membranes was kept stable after the temperature cycles, even after the one in hydrogen. This test showed that the membranes were stable and did not become brittle. This is because the $\mathrm{H}$ atoms in the Pd alloys travel through the Pd-X lattice, but are not incorporated into the structure, thereby minimising embrittlement problems [22].

\subsection{SEM images}

In order to analyse the effect of the $\mathrm{Cu}$ plating, the alloying and the hydrogen permeance tests in membrane metal layer, SEM images were taken, see Fig. 8 and Fig. 9. The membrane M2 was alloyed in an inert atmosphere, being tested at $673 \mathrm{~K}$ over 5 days with two temperature cycles in between: one in an inert atmosphere and the other one in hydrogen. In the SEM images in Fig. 8, the dark rough area on the left is the alumina support. Moving to the right there is an area where the Pd is anchored to the support, the next bright area is the Pd and the last and darker one is the $\mathrm{Cu}$ layer. Metal diffusion during alloying was not clear in the SEM images. Comparing images A and B from Fig. 8, Pd and Cu mixing was not clearly observed, even though the permeability value of the alloyed membrane implied that there had been Pd diffusion to the surface. In image $C$, after the hydrogen permeance and temperature cycles, it was still possible to differentiate the Cu layer, but the PdCu mixture was more extended. Table 3 presents the EDX composition values measured in this membrane after alloying and after the hydrogen permeance test. Based on the SEM images, EDX values, the alloying test in the GPS and the permeation measurements performed with the membranes, it can be concluded that from a certain point onwards, alloying has no substantial influence on permeance, even if it has not been completed. This can be clearly observed in Fig. 7, where the permeance value remained stable after alloying for a week at $723 \mathrm{~K}$ and five days of permeance testing that included thermal cycles.

SEM images were also taken to analyse the influence the membrane preparation steps have on surface morphology. Fig. 9 compares the M2 membrane surface after Cu plating (A), after alloying (B) and after the $\mathrm{H}_{2}$ test and temperature cycles in the GPS (C). After alloying, the surface was rougher and there were larger metal particles in the surface. Nevertheless, after the tests in the GPS, the large metal particles disappeared. The white ones were probably alumina particles from the membrane cutting prior to the SEM analysis. The surface morphology of specific areas in some of the membranes, such as spots and blackish areas, were analysed, but the morphology was similar to the average surface of the membranes.

Some membrane defects could be detected with SEM technology, such as no dense membranes, Fig. 10. Both membranes, M9 and M10, were found to be non porous after
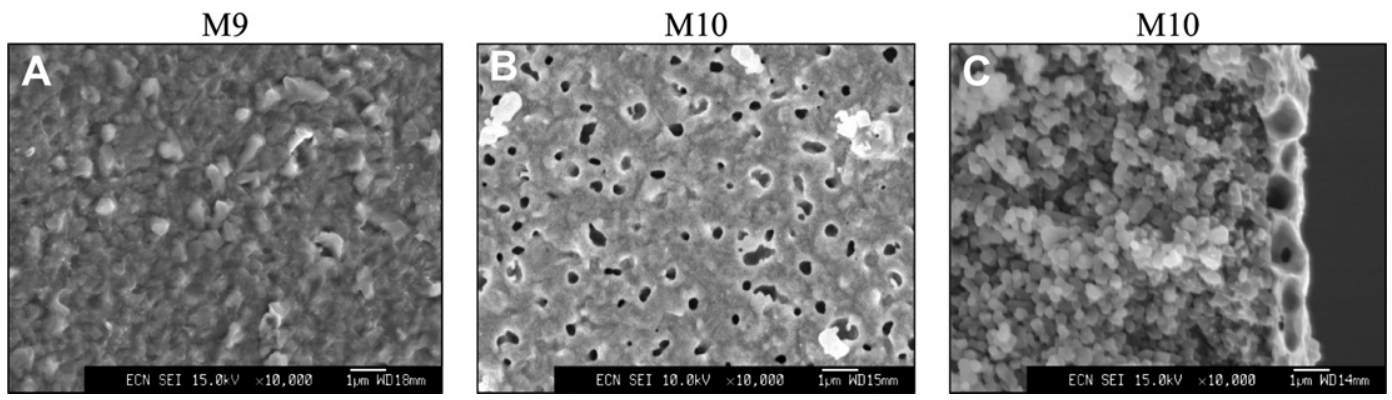

Fig. 10 - SEM images of two membranes that were no dense after alloying. 
the alloying step. There were some small holes and open surfaces (A) in the M9 membrane, but the metal surface in M10 was completely porous with holes between 0.2 and $0.5 \mu \mathrm{m}$ (B). These defects have also been observed in the literature, as the bcc/fcc mixed phase morphology is prone to defect formation along the grain boundary [7]. Large holes were also observed in the metal layer bulk (C). These results observed for the defective membranes, highlight the importance of the leak tests performed before testing membranes in the GPS.

\section{Conclusions}

The electroless plating method was suitable for thin PdCu metal layer membrane preparation as the resulting membranes had high hydrogen permeability, around $9.9 \times 10^{-11}$ and $2.1 \times 10^{-9}$ $\left(\mathrm{mol} /\left(\mathrm{sPa}^{\mathrm{n}} \mathrm{m}\right)\right)$, and were stable even when temperature cycles were performed in a hydrogen atmosphere. The plating step was quick and easy and the alloying step could be reduced to around $20 \mathrm{~h}$ for the small metal layer thickness of the prepared membranes, $0.9-1.5 \mu \mathrm{m}$. The weight increase method and SEM images were compared for measuring the metal layer thickness, with SEM being the more accurate method for such thin metal layers. The characterization of the membranes using the SEM images provided with valuable information about the influence of the metal alloying and hydrogen permeance on surface morphology. Based on the cross-section metal layer composition measurements taken with EDX it was concluded that a full alloying was not required to obtain a PdCu membrane with high and stable permeability.

PdCu membranes are promising candidates for advanced hydrogen separation modules. They are stable, non-brittle and record high hydrogen permeance values. Further work will include testing membrane permeance and stability in the presence of sulphur compound traces, as this is another clear reason for studying PdCu membranes.

\section{Acknowledgment}

The authors gratefully acknowledge the financial support for this work provided by the Spanish Ministry of Science and Innovation (ENE2007-67533-C02-02/ALT and PSEH2RENOV PSS-120000-2009-16) and by the Basque Government. The authors would also like to specifically acknowledge all the support received from the Energy research Centre of the Netherlands, Efficiency and Infrastructure unit, and thank Marijke Roos for the SEM images.

\section{R E F E R E N C E S}

[1] Bozzolo G, Garcés JE, Noebe RD, Abel P, Mosca HO. Atomistic modelling of surface and bulk properties of $\mathrm{Cu}$, Pd and the CU-Pd system. Prog Surf Sci 2003;73:79-116.

[2] Calles JA, Sanz R, Alique D. Comparison of composite Pd-Ag and Pd-Cu membranes over PSS supports for hydrogen separation. Proceedings of the 18th World Hydrogen Energy Conference; 2010. 2010. Detlef Stolten and Thomas Grube (Eds.), [Essen].
[3] Decaux C, Ngameni R, Solas D, Grigoriev S, Millet P. Time and frequency domain analysis of hydrogen permeation across PdCu metallic membranes for hydrogen purification. Int J Hydrogen Energy 2009;35:4883-92.

[4] Flanagan TB, Sakamoto Y. Hydrogen in disordered and ordered palladium alloys. Int J Hydrogen Energy 1994;19(2): $151-9$.

[5] Gallucci F, De Falco M, Tosti S, Marrelli L, Basile A. The effect of the hydrogen flux pressure and temperature dependence factors on the membrane reactor performances. Int $\mathrm{J}$ Hydrogen Energy 2007;32(16):4052-8.

[6] Gao H, Lin JYS, Li Y, Zhang B. Electroless plating synthesis, characterization and permeation properties of $\mathrm{Pd}-\mathrm{Cu}$ membranes supported on $\mathrm{ZrO} 2$ modified porous stainless steel. J Membr Sci 2005;265:142-52.

[7] Goldbach A, Yuan L, Xu H. Impact of the fcc/bcc phase transition on the homogeneity and behavior of PdCu membranes. Sep Purif Technol 2010;73:65-70.

[8] Guerrero R, Martínez JM. Updated hydrogen production costs and parities for conventional and renewable technologies. Int J Hydrogen Energy 2010;35(9):3929-36.

[9] Hou K, Hughes R. The effect of external mass transfer, competitive adsorption and coking on hydrogen permeation through thin Pd/Ag membranes. J Membr Sci 2002;206(1-2): 119-30.

[10] Hu X, Chen W, Huang Y. Fabrication of Pd/ceramic membranes for hydrogen separation based on low-cost macroporous ceramics with pencil coating. Int J Hydrogen Energy 2010;35:7803-8.

[11] Keuler J, Lorenzen L, Miachon S. Preparing and testing Pd films of thickness 1-2 micrometer with high selectivity and high hydrogen permeance. Sep Sci Technol 2002;37: 379-401.

[12] Khanuja M, Mehta BR, Shivaprasad SM. Two approaches for enhancing the hydrogenation properties of palladium: metal nanoparticle and thin film over layers. J Chem Sci 2008; 120(6):573-8.

[13] Kulprathipanja A, Alptekin GO, Falconer JL, Way JD. Effects of water gas shift gases on Pd-Cu alloy membrane surface morphology and separation properties. Ind Eng Chem Res 2004;43:4188-98.

[14] Kulprathipanja A, Alptekin GO, Falconer JL, Way JD. Pd and Pd-Cu membranes: inhibition of $\mathrm{H}_{2}$ permeation by $\mathrm{H} 2 \mathrm{~S}$. J Membr Sci 2005;254(1-2):49-62.

[15] Li A, Liang W, Hughes R. Fabrication of dense palladium composite membranes for hydrogen separation. Catal Today 2000;56(1-3):45-51.

[16] Li A, Lim CJ, Grace JR. Staged-separation membrane reactor for steam methane reforming. Chem Eng J 2008; 138:452-9.

[17] Løvvik OM. Surface segregation in palladium based alloys from density-functional calculations. Surf Sci 2005;583: $100-6$.

[18] Lu GQ, Diniz da Costa JC, Duke M, Giessler S, Socolow R, Williams RH, et al. Inorganic membranes for hydrogen production and purification: a critical review and perspective. J Colloid Interface Sci 2007;314(2):589-603.

[19] Ma Y, Ceylan Akis B, Ayturk E, Guazzone F, Engwall E, Mardilovich I. Characterization of intermetallic diffusion barrier and alloy formation for $\mathrm{Pd} / \mathrm{Cu}$ and $\mathrm{Pd} / \mathrm{Ag}$ porous stainless steel composite membranes. Ind Eng Chem Res 2003;43:2936-45.

[20] McKinley DL, Nitro WV. Method for hydrogen separation and purification. United States patent 3.439.474; 1969.

[21] Morreale BD, Ciocco MV, Enick RM, Morsi BI, Howard BH, Cugini AV, et al. The permeability of hydrogen in bulk palladium at elevated temperatures and pressures. J Membr Sci 2003;212:87-97. 
[22] Miller JB, Morreale BD, Gellman AJ. The effect of adsorbed sulfur on surface segregation in a polycrystalline Pd70Cu30 alloy. Surf Sci 2008;602:1819-25.

[23] Nam SE, Lee KH. Hydrogen separation by Pd alloy composite membranes: introduction of diffusion barrier. J Membr Sci 2001;192:177-85.

[24] Oita M, Matsuoka M, Iwakura C. Deposition rate and morphology of electroless copper film from solutions containing 2,2'-dypyridyl. Electrochim Acta 1997;42(9): 1435-40.

[25] Paglieri SN, Foo KY, Way JD, Collins JP, Harper-Nixon DL. A new preparation technique for $\mathrm{Pd} /$ Alumina membranes with enhanced high-temperature stability. Ind. Eng Chem Res 1999;38:1925-36.

[26] Peters TA, Stange M, Klette H, Bredesen R. High pressure performance of thin $\mathrm{Pd}-23 \% \mathrm{Ag} /$ stainless steel composite membranes in water gas shift gas mixtures; influence of dilution, mass transfer and surface effects on the hydrogen flux. J Membr Sci 2008;316(1-2):119-27.

[27] Pomerantz N, Ma YH. Effect of $\mathrm{H}_{2} \mathrm{~S}$ on the performance and long-term stability of $\mathrm{Pd} / \mathrm{Cu}$ membranes. Ind Eng Chem Res 2009;48:4030-9.

[28] Roa F, Block MJ, Way JD. The influence of alloy composition on the $\mathrm{H}_{2}$ flux of composite Pd-Cu membranes. Desalination 2002;147:411-6.

[29] Roa F, Way JD. Alloy composition effect on the n-value for $\mathrm{H}_{2}$-selective $\mathrm{Pd}$ membranes. Fuel Chem Division Preprints 2003a;48:335-6.

[30] Roa F, Way JD. Influence of alloy composition and membrane fabrication on the pressure dependence of the hydrogen flux of palladium-copper membranes. Ind Eng Chem Res 2003b; 42:2835-5827.
[31] Roa F, Way JD, McCormick RL, Paglieri SN. Preparation and characterization of $\mathrm{Pd}-\mathrm{Cu}$ composite membranes for hydrogen separation. Chem Eng J 2003c;93:11-22.

[32] Rothenberger KS, Cugini AV, Howard BH, Killmeyer RP, Ciocco MV, Morreale BD, et al. High pressure hydrogen permeance of porous stainless steel coated with a thin palladium film via electroless plating. J Membr Sci 2004;244: 55-68.

[33] Shi L, Goldbach A, Zeng G, Xu H. Preparation and performance of thin-layered $\mathrm{PdAu} /$ ceramic composite membranes. Int J Hydrogen Energy 2010;35(9):4201-8.

[34] Shu J, Grandjean BPA, Kaliaguine S. Effect of $\mathrm{Cu}(\mathrm{OH})_{2}$ on electroless copper plating. Ind Eng Chem Res 1997;36:1632-6.

[35] Tosti S, Adrover A, Basile A, Camilli V, Chiappetta G, Violante V. Characterization of thin wall Pd-Ag rolled membranes. Int J Hydrogen Energy 2003;28(1):105-12.

[36] Weil R, Paquin R. The relation between brightness and structure in electroplated nickel. J Electrochem Soc 1960;107: 87-91.

[37] Wu LQ, Xu N, Shi J. Preparation of a palladium composite membrane by an improved electroless plating technique. Ind Eng Chem Res 2000;39(2):342-8.

[38] Yuan L, Goldbach A, Xu H. Real-time monitoring of metal deposition and segregation phenomena during preparation of PdCu membranes. J Membr Sci 2008;322(1):39-45.

[39] Yuan L, Goldbach A, Xu H. Segregation and H2 transport rate control in body-centered cubic PdCu membranes. J Phys Chem B 2007;111:10952-8.

[40] Zhang X, Wang W, Liu J, Sheng S, Xiong G, Yang W. Hydrogen transport through thin palladium-copper alloy composite membranes at low temperatures. Thin Solid Films 2008; 516(8):1849-56. 